\title{
Co-morbid Personality Disorders among Alcohol Dependent Patients
}

\author{
Jay Kumar Ranjan', Om Prakash', Masroor Jahan', Amool R. Singh
}

The aim of the present research investigation was to describe the co-morbid personality disorder among alcohol dependent patients and to compare it with those of the normal population. Based on purposive sampling technique, 50 alcohol dependent patients were selected from psychiatric inpatient of RINPAS and 50 normal participants were selected from the general population. Both the groups were matched for age,gender and socioeconomic level. All participants were assessed with Millon Clinical Multi-axial Inventory (MCMI)-III. The obtained responses were scored by using standard scoring procedure and subsequently statistically analyzed by using of $x 2$ test and step wise discriminant analysis. Results revealed that alcohol dependent patients have more co-morbid pathological personality traits and disorders in comparison to normal control group. Of the alcohol-dependent patients, dependent personality disorder was most prevalent followed by antisocial, negativistic and compulsive personality disorders.

Key word: Co-morbid, Personality Disorder, Alcohol Dependents

\section{INTRODUCTION:}

Alcohol abuse and dependence are among the most prevalent mental disorders in the general population. In a study conducted in rural community in Bihar, prevalence of alcohol/drug use was $28.8 \%$. Meena et al. (2002) revealed a prevalence rate of alcohol use as $19.78 \%$ in an urban population in Rohtak district of Haryana'. In a metaanalysis of 13 psychiatric epidemiological studies, Reddy (1998) found the prevalence rate of alcohol/drug use as 6.9 per 1000 . Recently, in community survey in rural and slum area of Chandigarh, $6.88 \%$ individuals of total population surveyed fulfilled dependence criteria of ICD10 . This problem obviously is a significant public health challenge.

In spite of growing interest in alcohol related issues, it remains difficult to accurately define the relationship between personality disorders (PDs) and alcohol dependence. Available literature in the area of prevalence of personality disorder in alcoholics reports a prevalence rate ranging from as low as $22-44 \% 0^{3,0 .}$ to as high as 58 $78 \% \%^{\mathrm{s}, 10}$.

Similarly, the number and types of PDs found in the literature are very heterogeneous. The most prevalent in the clinical trials have been dependent and histrionic ; paranoid and obsessive compulsive ". "; antisocial "; narcissistic ${ }^{13}$; and avoidant and borderline ${ }^{2,4}$.

Diagnostic disparity and the lack of consistency are found in the literature with respect to the prevalence, and the types of personality disorders associated with alcohol dependence. There is also dearth of Indian studies in this intent. So, main aim of the present study was to assess prevalence and types of co-morbid personality disorders among alcohol dependent patients, and its comparison to normal controls.

\section{METHODOLOGY:}

\section{Participants and Procedure:}

To calculate sample size, we used alpha $=0.05$, medium effect size $=0.3$ and set the power at 0.80 of chi square for comparing across alcohol dependent patients and normal controls. Power analysis resulted in that at least a total of 100 sample size is required (Cohen, 1988).s. Based on purposive sampling technique, the participants were selected $^{\prime}$. The sample for this study consisted of 50 patients of alcohol-dependence and 50 normal participants from the general population. All patients were taken from de-addiction ward of Ranchi Institute of Neuro-Psychiatry and Allied Sciences, Kanke, Ranchi. All the participants of normal control group were selected from Ranchi and nearby places. Alcohol dependence patients with fulfilling ICD-10 (1992) diagnostic criteria, age range of 18-55yrs, educated up to std. VIII and currently abstinent, in protected environment ( 7 days to 14 days) were included. Alcohol dependence patients having any other co-morbid psychiatric disorder, and organic, and neurological disorders were excluded. Co-operative normal participants, age range of $18-55 \mathrm{yrs}$, educated up to std. 8 were included in the sample. Normal participants with a history of organic mental disorder, head injury and other neurological disorders

Eastern J. Psychiatry Vol. 14, No. 1-2 
were excluded. Initially, an informed consent was taken from all the participants and they were also explained about the purpose of the study. The Millon Clinical Mutiaxial Inventory was administered and scored following standard procedure ${ }^{17}$.

\section{Measures:}

The following tools have been used in the study:

Socio-demographic Data sheet: The Socio-demographic data sheet was custom made, which contained the sociodemographic information of the subjects.

The Millon Clinical Multiaxial Inventory-3rd Ed. (MCMI-III) : MCMI-III is a 175 items true-false selfreport questionnaire especially designed to measure personality traits and disorder. The scales are clustered into two groups: 14 PD scales and 10 clinical syndrome scales. It also has a Social Desirability scale (Scale Y), a Debasement scale (Scale Z) and a Validity scale (Scale V) which includes 3 bizarre or highly improbable items to see if responses are consistent throughout. Traditionally, Base Rate (BR) scores of 75 to 84 indicate the presence of clinically significant traits. BR scores of 85 or greater indicate the high probability of that clinical diagnosis ${ }^{18.19}$. For clinical significance it would then be more appropriate to regard a BR score around 70 as significant in group comparisons. Reliability and validity of the MCMI-III has consistently been demonstrated ${ }^{17,19}$.

\section{Statistics Used:}

The obtained responses of alcohol dependent patients and normal controls on MCMI-III were analyzed by using of $x$ test \& Stepwise Discriminate Analysis with the help of Statistical Package for Social Sciences (SPSS) -17.

\section{RESULTS:}

Present research study assessed co-morbid personality disorder among alcohol dependent cases and normal controls.

Table 1 shows characteristics of MCMI-III profile of patients with alcohol dependence and normal controls.

\begin{tabular}{|c|c|c|l|c|}
\hline Profile Type & ADS (\%) & Normal (\%) & df & $\mathbf{X}^{2}$ \\
\hline Personality trait \& disorder & $34(68 \%)$ & $19(38 \%)$ & 1 & \\
\hline Normal Profile & $6(12 \%)$ & $23(56 \%)$ & 1 & $23.29(0.001)$ \\
\hline Fake Good & $2(4 \%)$ & $5(10 \%)$ & 1 & $2.57(\mathrm{NS})$ \\
\hline Fake Bad & $8(16 \%)$ & $3(6 \%)$ & 1 & $4.54(0.05)$ \\
\hline
\end{tabular}

Among total 50 patients of alcohol dependence, $12 \%$ had normal profile and $20 \%$ profiles were invalid. Among 50 normal controls, 56\% profiles were normal and 16\% profiles were invalid. A total of $68 \%$ alcohol dependent patients were having pathological personality traits or disorders and a total of $38 \%$ normal participants were having pathological personality traits or disorders.

Table 2 shows types of pathological personality traits and disorders among patients with alcohol dependence and normal controls.

\begin{tabular}{|c|c|c|c|c|}
\hline Personality Type & ADS (\%) & Normal (\%) & df & $\mathbf{X}^{2}$ \\
\hline Schizoid & $4(8 \%)$ & $3(6 \%)$ & 1 & $0.28(\mathrm{NS})$ \\
\hline Avoidant & $2(4 \%)$ & $4(8 \%)$ & 1 & $1.33(\mathrm{NS})$ \\
\hline Depressive & $3(6 \%)$ & $0(0 \%)$ & 1 & $6.00(0.01)$ \\
\hline Dependent & $6(12 \%)$ & $3(6 \%)$ & 1 & $3.84(0.05)$ \\
\hline Histrionic & $4(8 \%)$ & $1(2 \%)$ & 1 & $4.84(0.05)$ \\
\hline Narcissistic & $2(4 \%)$ & $3(6 \%)$ & 1 & $0.04(\mathrm{NS})$ \\
\hline Antisocial & $4(8 \%)$ & $0(0 \%)$ & 1 & $8.00(0.01)$ \\
\hline Compulsive & $5(10 \%)$ & $1(2 \%)$ & 1 & $5.33(0.01)$ \\
\hline Negativistic & $4(8 \%)$ & $1(2 \%)$ & 1 & $7.17(0.01)$ \\
\hline $\begin{array}{c}\text { Masochistic, Sadistic, } \\
\text { Schizotypal, Borderline, } \\
\text { Paranoid }\end{array}$ & $0(0 \%)$ & $0(0 \%)$ & - & - \\
\hline \multicolumn{2}{|c|}{} & & & \\
\hline
\end{tabular}

The most prevalent pathological personality traits or disorders among the alcohol dependent patients was dependent (12\%), followed by obsessive-compulsive $(10 \%)$, antisocial, schizoid, negativistic and histrionic $(8 \%$ each), depressive (6\%) and finally narcissistic and avoidant (4\% each). In the normal control group, the most prevalent pathological personality traits and disorders was avoidant $(8 \%)$ followed by narcissistic, dependent, schizoid (6\% each) and obsessive-compulsive, negativistic and histrionic (2\% each).

With respect to comparison of personality disorders between both the groups, there were statistically significant

differences in different personality traits and disorders. Antisocial $(\boldsymbol{x}=8.0, \mathrm{p}<0.01)$, depressive $(\boldsymbol{x}=6.0, \mathrm{p}<0.01)$, dependent $(\boldsymbol{x}=3.84 \mathrm{p}<0.05)$, histrionic $(\boldsymbol{x}=4.84, \mathrm{p}<$ $0.05)$, and negativistic $(\boldsymbol{x}=7.17, \mathrm{p}<0.01)$ personality traits and disorders were more associated with alcohol-dependent patients than to normal control group.

A stepwise discriminant analysis was performed using types of personality disorders as predictors in alcohol dependent group and normal controls (Table 3). 
Table 3: Discriminative Classification based on the assessment of MCMI-III

\begin{tabular}{|c|c|c|c|c|}
\hline \multirow{4}{*}{ Count } & group & \multicolumn{2}{|c|}{ Predicted Group Membership } & Total \\
\cline { 2 - 5 } & & Ads (\%) & Normal (\%) & \\
\cline { 2 - 5 } & Ads (\%) & $31(70.5)$ & $13(29.5)$ & 44 \\
\cline { 2 - 5 } & Normal (\%) & $21(42.0)$ & $29(58.0)$ & 50 \\
\hline
\end{tabular}

Of the original 94 subjects, 6 were dropped from analysis because of missing data. Missing data appeared to be randomly scattered throughout groups and predictors. The value of discriminant function was statistically significant between patients with alcohol dependence and normal controls. Dependent personality type was only reliable predictor which potentially differentiated patients with alcohol dependent and normal controls (Lamda $=.972$, $\mathrm{df}=92, \mathrm{P}>0.05)$. The analysis brings the percentage with a correct assignment to $63.82 \%$, the sensitivity with respect to the alcohol dependent group was $70.5 \%$ and with respect to the normal control group was 58\%. Correct assignment to the predicted alcohol dependent group was about 57.40 and to the normal controls was about $69.07 \%$.

\section{DISCUSSION:}

The most salient finding is that $68 \%$ of the alcoholic dependent patients had co-morbid pathological personality disorders and traits (as per norms mentioned in MCMIIII) compared to $38 \%$ of the normal controls. Similar findings have been reported in an Indian study of Sattar et al.20, who also found that $55 \%$ of alcohol dependent patients had co-morbid pathological personality traits and disorders. Another Indian study 21 has also reported that $33 \%$ of drug dependent patients had co-morbid personality disorder. Similarly, in a community based study of general population in develop countries, de Girelamo, et al.22 reported $10.3 \%$ to $13.3 \%$ prevalence rate of PDs in general population.

Findings of present study are consistent with the findings of previous studies; who have also reported that PDs were very common in alcohol dependent patients than normal controls. With respect to the types of PDs, the most prevalent PD in all groups was dependent personality disorder. Obsessive-compulsive, antisocial, negativistic, schizoid, depressive, narcissistic, avoidant and histrionic PDs were more associated to alcohol-dependent patients than to normal control group ${ }^{2 s, \ldots, 1,1,1,2,3}$.

The result of the present research study shows that dependent, obsessive-compulsive, antisocial, negativistic, histrionic personality traits and disorders were most commonly prevalent among alcohol dependent patients.
Previous researches have also reported that the most common personality disorder were dependent and histrionic ", "; paranoid and obsessive compulsive "; antisocial "; narcissistic and avoidant" However, our findings are contradictory to some aspects of previous researches ${ }^{10}$... paranoid and borderline personality are commonly prevalent among alcohol dependent group. Discrepancy in the findings with previous researches may be because they have taken samples from community and outpatient clinics.

With respect to the clusters of PDs, the presence of clusters $\mathrm{B}$ and $\mathrm{C}$ was higher among alcohol dependent patients than in the clinical and normative groups. These findings validate the approach in the previous studies carried out by Echebur' ua et al."

This study has both theoretical and applied implications. The accurate understanding of personality disorder in alcohol dependent patients could help to guide further research regarding treatment decisions for psychological management according to the patient's personality pattern. Small sample size and not inclusion of female sample were limitations of the present study.

\section{References:}

1. Jena R, Shukla TR, Pal H. Drug abuse in rural communities in Bihar: Some psychosocial correlates. Indian Journal of Psychiatry, 1996; 38: 43-46.

2. Meena, Khanna P, Vohra AK, Rajput R. Prevalence and pattern of alcohol and substance abuse $\mathrm{n}$ urban area of Rohtak city. Indian Journal of Psychiatry, 2002; 44: 348-352.

3. Reddy MV, Chandrashekhar CR. Prevalence of mental and behavioural disorder in India. Indian Journal of Psychiatry, 1998; 40:149-157.

4. Chavan BS, Arun P, Bhargava R, Singh GP. Prevalence of alcohol and drug dependence in rural and slum population of Chandigarh: A community survey. Indian Journal of Psychiatry, 2010; 49 (1): 44-48.

5. Grant BF, Stinson FS, Dawson DA, et al. Co-occurrence of 12 month alcohol and drug use disorders and personality disorders in the United States. Archives of General Psychiatry, 2004; 61:361368 .

6. Echebur'ua E, Bravo de Medina R, and Aizpiri J. Alcoholism and personality disorders: An exploratory study. Alcohol and Alcoholism, 2005; 40: 323-326.

7. Echebur'ua E, Bravo de Medina R, and Aizpiri J. Comorbidity of alcohol dependence and personality disorders: a comparative study. Alcohol and Alcoholism, 2007; 42 (6): 618-622.

8. DeJong CA, Van den Brink W, Harteveld FM et al. Personality disorders in alcoholics and drug addicts. Comprehensive Psychiatry, 1993; 34: 87-94. 
9. Morgenstern J, Langenbucher J, Labouvie E, et al. The comorbility of alcoholism and personality disorders in a clinical population: prevalence rates and relation to alcohol typology variables. Journal of Abnormal Psychology, 1997; 106: 74-84.

10. Fern'andez-Montalvo J, Landa N, L'opez GoÜni JJ, et al. Personality disorders in alcoholics: A comparative study between the IPDE and the MCMI-II. Addictive Behaviors, 2006; 31:14421448 .

11. Nurnberg HG, Rifkin A, \& Doddi S. A systematic assessment of the comorbidity of DSM-III-R personality disorders in alcoholic outpatients. Comprehensive Psychiatry, 1993; 34: 447-454.

12. Powell G, \& Peveler R. Nature and prevalence of personality disorders amongst patients receiving treatment for alcohol dependence. Journal of Mental Health, 1996; 5: 305-314.

13. Pettinati H, Pierce J, Pierce J, et al. The relationship of Axis II personality disorders to other known predictors of addiction treatment outcome. The American Journal of Addictions, 1999; 8: 136-147.

14. Fern'andez-Montalvo J, Landa N, L'opez Goni J J, et al. Trastornos de personalidad en alcoh'olicos: un estudio descriptivo. Revista de Psicopatolog'1 a y Psicolog'1a Cl'1nica, 2002; 7: 217 225. (cited from the article of Fern'andez-Montalvo et al. 2006)

15. Cohen J. Statistical Power Analysis for the Behavioral Sciences, Second Edition. Hillsdale, New Jersey: Lawrence Erlbaum Associate, Inc, 1988.

16. Cochran WG. Sampling Techniques. New York, John Willey and Sons, 1963.
17. Millon T. Millon Clinical Multiaxial Inventory-III, Manual. Minneapolis, MN: National Computer Systems, 1994.

18. Choca JP. Interpretive guide to the Millon Clinical Multiaxial Inventory (3rd ed.). Washington, DC: American Psychological Association, 2004.

19. Strack S. Combined use of the PACL and the MCMI-III ${ }^{\mathrm{TM}}$ to assess normal range of personality styles. In R. J. Craig (Ed.), New directions in interpreting the Millon Clinical Multiaxial InventoryIII (MCMI-III $\left.{ }^{\mathrm{TM}}\right)$ Hoboken, NJ: John Wiley \& Sons, 2005.

20. Sattar FA, Raju MS, Goyal S. Comorbidity in alcohol dependence syndrome. Indian Journal of Psychiatry, 1998; 40: 22.

21. Kishore P, Lal N, Trivedi JK. A study of comorbidity in psychoactive substance dependence patients. Indian Journal of Psychiatry, 1994; 36: 133-137.

22. DeGirolamo G, Reich JH. Personality Disorders (Epidemiology of Mental Disorders and Psychosocial Problems). Geneva: World Health Organization, 1993.

23. Driessen M, Veltrup C, Wetterling T. et al. Axis I and Axis II comorbidity in alcohol dependence and the types of alcoholism. Alcohol Clinical Experimental Research, 1998;22: 77-86.

1- Research Officer, 2- M. Phil. trainee, 3-Associate Professor, 4- Professor \& Head, Department of Clinical Psychology, RINPAS, Kanke, Ranchi-6. 